\title{
əTemporal Changes in Land Surface Coupling Strength: An Example in a Semi-Arid Region of Australia
}

\author{
Min-Hui Lo, ${ }^{\mathrm{a}}$ Wen-Ying Wu,${ }^{\mathrm{a}, \mathrm{c}}$ Lois Iping Tang,,${ }^{\mathrm{a}, \mathrm{d}}$ Dongryeol Ryu, ${ }^{\mathrm{b}}$ Mehnaz Rashid, ${ }^{\mathrm{a}}$ AND Ren-Jie Wu ${ }^{\mathrm{a}}$ \\ ${ }^{a}$ Department of Atmospheric Sciences, National Taiwan University, Taipei, Taiwan \\ ${ }^{\mathrm{b}}$ Melbourne School of Engineering, The University of Melbourne, Victoria, Australia
}

(Manuscript received 9 April 2020, in final form 20 November 2020)

\begin{abstract}
One of the critical components in understanding the climate system is the interaction between the land and the atmosphere. Whereas previous studies on land-atmosphere coupling mostly focus on its spatial hotspots, we explore the temporal evolution of land surface coupling strength (LCS) during a large-scale flood event in a semiarid region in northern Australia. The LCS indicates the relationship between soil moisture and latent heat flux, and the spatiotemporal variability in precipitation and soil water strongly affects the variability of LCS. The LCS is usually positive in the semiarid climate, where evapotranspiration (ET) occurs under the soil moisture-limited regime and thus increases with soil moisture. However, our analyses of combined land surface modeling and observational datasets show high temporal variability of LCS in the course of the extreme flood event followed by a drying period. The wet regions transferred the ET regime from the soil moisture-limited to the transition section, weakening the linear growth of ET with soil moisture, which resulted in the decline of LCS. The LCS remained weak until the flood retreated and the soil water approached the prestorm average state. Such temporal variation of the LCS has important implications for realistic parameterization of the land-atmosphere coupling and consequently improving subseasonal to seasonal climate forecast.
\end{abstract}

KEYWORDS: Australia; Atmosphere-land interaction; Flood events; Evapotranspiration

\section{Introduction}

Feedback between the land and the atmosphere is a critical component in the climate system. Understanding how land surface processes affect climate can help improve climate model simulations on the subseasonal to seasonal time scale. The relationship between soil moisture and surface water/ energy fluxes is seen as the "terrestrial" segment of landatmosphere coupling (interactions). The other segment, the "atmospheric" one, refers to the influence of surface fluxes on the boundary layer and tropospheric condition, including precipitation (Dirmeyer 2011). The atmosphere is heated up by sensible heat flux and moistened by evapotranspiration (ET) from the surface, and the partitioning between sensible and latent heat fluxes is influenced by soil moisture. Thus, inaccurate soil moisture information has been regarded as a major source of

¿ Denotes content that is immediately available upon publication as open access.

Supplemental information related to this paper is available at the Journals Online website: https://doi.org/10.1175/JCLI-D-200250.s1.

\footnotetext{
${ }^{\mathrm{c}}$ Current affiliation: Department of Geological Sciences, Jackson School of Geosciences, The University of Texas at Austin, Austin, Texas.

${ }^{\mathrm{d}}$ Current affiliation: Department of Earth and Planetary Sciences, Harvard University, Cambridge, Massachusetts.
}

Corresponding author: Min-Hui Lo,minhuilo@ntu.edu.tw uncertainty in climate model simulations (e.g., Schär et al. 1999; Koster et al. 2004; Seneviratne et al. 2010; Dirmeyer et al. 2013). Responses of ET to soil moisture can be explained by the Budyko curve (Budyko 1974). The function illustrates the relationship between soil moisture and the ratio of actual ET (AET) to the possible maximum amount of ET, the potential ET (PET). When the soil moisture is under a dry condition, ET fraction grows linearly with the soil moisture. Under this condition, the so-called dry regime or soil moisture-limited regime, AET is mainly controlled by the available soil moisture and plant available water. On the contrary, as the soil moisture increases and AET approaches PET, the local ET is limited by the available input energy defined by the net radiation, vapor pressure deficit, and wind speed. This latter condition is called the wet regime or energy-limited regime. In the soil moisture-limited regime, adding water to soil results in higher ET; however, in the energy-limited regime, added water leads to no or minimal contribution to ET (Seneviratne et al. 2010). A transition zone usually exists between the soil moisture-limited regime and the energy-limited regime (Koster et al. 2004; Seneviratne et al. 2010).

The changes in soil moisture generally have negative feedbacks to the near-surface air temperature due to the changes in ET (Cheruy et al. 2013; Lo and Famiglietti 2013; Chou et al. 2018). When the liquid water transforms into water vapor through ET, the atmosphere takes the latent heat away from the local land surface and releases the energy nonlocally or remotely (Wey et al. 2015). Depending on the relative strengths of relevant factors such as local atmospheric stability and large-scale circulation, the condensation of water vapor may result in precipitation formation, thus bringing the water back to the land surface. The feedback between soil moisture and precipitation, however, can be either positive or negative. 
A positive soil moisture-rainfall relationship has been observed in Illinois (Findell and Eltahir 1997), Kansas (Eltahir 1998), and the United States as a whole (Koster et al. 2003), whereas enhanced precipitation accompanied by drier soil has been observed in West Africa, the Sahel, and Australia (Hohenegger et al. 2009; Taylor et al. 2012; Guillod et al. 2015). The dominant feedback between soil moisture and precipitation often depends on soil wetness (Hsu et al. 2017; Holgate et al. 2019), precipitation frequency, and the temporal retention of soil moisture (Wei et al. 2008).

Precipitation can also exhibit weak or no coupling to soil moisture variations. For example, precipitation would not be influenced by soil moisture when the soil is too wet; it would no longer be a limiting factor because ET is controlled by available energy rather than soil moisture. In general, the land surface and the atmosphere show tight coupling in the transition zone between the wet and dry climate regimes (Seneviratne et al. 2010). Previous studies showed that the "hot spots" of land-atmospheric coupling, where soil moisture condition was considered to influence the troposphere, mainly existed at regions of intermediate soil wetness between arid and humid conditions (Koster et al. 2004; Guo et al. 2006; Dirmeyer 2011). Guo and Dirmeyer (2013) further pointed out that the land-atmosphere coupling strength (LCS) can show interannual variability. The coupling tends to strengthen during anomalously wet years for arid zones and anomalously dry years for wet regions. Considering the sensitivity of precipitation to soil moisture in regions under the transition zone, where proper soil moisture information is important, can improve the intraseasonal to subseasonal forecast skill (Koster et al. 2010; Zhao et al. 2019). Previous studies also showed that soil moisture could influence land-atmosphere coupling through delay and buffering effects, which might further affect the persistence of climate extremes (e.g., Entekhabi et al. 1996; Elthahir 1998; Lo and Famiglietti 2010). Therefore, the spatiotemporal distribution of soil moisture is critical for numerical climate prediction.

While previous studies mostly focused on the spatial distribution of the LCS hot spots in particular seasons or the whole year (Dirmeyer et al. 2006; Chen and Zhang 2009), the temporal evolution of the LCS at a particular location under an extreme event has not been explored thoroughly yet. Only a few studies, such as that of Basara and Christian (2018), reported subseasonally varying land-atmosphere coupling and stronger coupling in the terrestrial segment under spatially and temporally warm conditions in the Great Plains of the United States. In this study, we present the impact of a single hydrological event on LCS over time and demonstrate how their interaction contributes to the subseasonal variation of the land-atmosphere coupling.

With high spatial and temporal variability in precipitation, a region in northern Australia $\left(16^{\circ}-21^{\circ} \mathrm{S}, 125^{\circ}-145^{\circ} \mathrm{E}\right)$ is chosen as our testbed to explore temporal variations of LCS in such semiarid regions with a small portion of the tropical region included. Annual rainfall in this region is mainly attributed to the thunderstorms and the occasional tropical cyclones (http:// www.bom.gov.au). Located in Oceania between the South Pacific Ocean and the Indian Ocean, Australia is influenced by many kinds of natural climate variations, such as El NiñoSouthern Oscillation (ENSO), the Indian Ocean dipole (IOD), and the southern annular mode (SAM). These climate oscillations as a combination led to extreme rainfall and subsequent large flood events in 2010/11 (Fasullo et al. 2013). Due to the enormous amount of water transported mainly to the Australian continent during this extreme flooding event, the global sea level dropped by approximately $5 \mathrm{~mm}$ (Boening et al. 2012), which coincided with matching increases in terrestrial water storage (TWS) over Australia and South America estimated by the Gravity Recovery and Climate Experiment (GRACE; Tapley et al. 2004). The increase in TWS over Australia persisted longer than that in other continents (Fasullo et al. 2013). This is caused by Australia's unique hydrological environment, where some large semiarid and arid basins in Queensland and South Australia are very flat and endorheic (Fasullo et al. 2013). The condition typically leads to large transmission loss allowing only a small fraction of precipitation for runoff, and most of the rest returns to the atmosphere through ET or infiltrates into soil (Costelloe et al. 2003; McMahon et al. 2008). For example, Jarihani et al. (2015) report that the runoff ratio in the northern part of the Diamantina Catchments (near the center of our study region) was 0.07 in 2010/11 when all rainfall events were counted and 0.24 when only rainfall events greater than $20 \mathrm{~mm}$ were included.

The persistence of a wet anomaly of soil moisture (soil moisture memory) after the precipitation events has implications for subseasonal to seasonal forecasting (Koster et al. 2000). How this delayed response of ET affects the land-atmosphere coupling strength is the main focus of this study. Therefore, we applied a land surface coupling index from Dirmeyer (2011) to diagnose the impact of soil moisture variation on the coupling strength in northern Australia during the flood event in 2010/11. Section 2 introduces the data and model we use to verify land water content, and the index we use to estimate the landatmosphere coupling strength is also discussed. Section 3 describes the results by which the change in surface ET condition is found during the flood. Implications of this study and future work are further included in sections 4 and 5 .

\section{Data and method}

\section{a. Gravity Recovery and Climate Experiment}

We use Gravity Recovery and Climate Experiment (GRACE) data to evaluate the simulated TWS over Australia. GRACE (Tapley et al. 2004) is a collaborative Earth observation mission by the National Aeronautics and Space Administration (NASA) and the German Aerospace Center that maps global-scale gravity change regularly. With the changes in distance between two satellites, GRACE has been making accurate measurements of changes in TWS in time scales of monthly or longer both over the land (Swenson et al. 2003) and ocean (Chambers et al. 2004) since its launch in March 2002. The GRACE mission provides an estimation of variations in TWS for areas larger than $150000 \mathrm{~km}^{2}$ (Swenson et al. 2006). Several studies have compared GRACE-derived TWS to in situ observations (Rodell et al. 2004a; Swenson et al. 2006) and hydrological models (Ramillien et al. 2004; Syed et al. 2008). Both in situ and model results mostly showed reasonable agreement with the GRACE TWS. The official 
GRACE Science Data System releases monthly gravity solutions from three different processing centers: the GFZ (Geoforschungs Zentrum Potsdam), CSR (Center for Space Research at University of Texas, Austin), and JPL (Jet Propulsion Laboratory). Here, we use the JPL RL06M (Release 06 generated by the mascons solution; Wiese et al. 2018; Watkins et al. 2015; Wiese et al. 2016) to calculate TWS. Further information about the data is available at https:// grace.jpl.nasa.gov/data/get-data/jpl_global_mascons/. We also utilize other GRACE products, GRACE_CSR RL05 (Save et al. 2016), GRACE_GFZ RL05 (Dahle et al. 2012), and GRACE_JPL RL05 (Wiese et al. 2015), which also give consistent results (shown in Fig. S1 in the online supplemental material).

\section{b. Community Land Model version 4}

The Community Land Model version 4 (CLM4; Oleson et al. 2010; Lawrence et al. 2011) is employed to simulate hydrological fluxes and states in the study region. CLM4 is the land component in the Community Earth System Model (CESM; Hurrell et al. 2013). To simulate land hydrology over Australia, we conducted offline CLM4 simulation with 3-hourly forcing from Global Land Data Assimilation System (GLDAS; Rodell et al. 2004b) after correcting bias in the precipitation having the same amount of monthly precipitation using the Australian Water Availability Project (AWAP; Jones et al. 2009; Raupach et al. 2009, 2012). AWAP is an interpolated gauge precipitation dataset available over entire Australia managed by the National Climate Centre, Australian Bureau of Meteorology. For spinup simulations, atmospheric forcing from 1980 to 2013 was applied for five cycles, with 170 years in total. Then, the simulation for analysis was run from 1964 to 2013 with a spatial resolution of $0.5^{\circ} \times 0.5^{\circ}$. Note that GLDAS provides two versions of data: GLDAS-1 and GLDAS-2. GLDAS-1 forcing data is over the record from 1979 to the present, whereas GLDAS-2 is from 1948 to 2010. Due to the changes in data sources for GLDAS-1 forcing, GLDAS-1 exhibits some discontinuous and unnatural trends, especially from 1995 to 1997 (Rui and Beaudoing 2020). Compared to GLDAS-1, the forcing data from GLDAS-2 feature greater consistency with time. Considering the limitation of data availability and consistency, we combined GLDAS-2 (1964-99) and GLDAS-1 (2000-13) to construct the model forcing for the entire simulation period, 1964-2013. The average precipitation from GLDAS is lower than TRMM and AWAP, especially during the peak precipitation periods as shown in Fig. S2. Moreover, the standard deviation (seasonal and interannual variations) from GLDAS is smaller than the two datasets. Hence, we corrected the GLDAS precipitation bias using monthly AWAP data. On top of GLDAS forcing, monthly-accumulated precipitation is scaled to match AWAP values.

To evaluate the overall water balance of CLM4 at the continental scale and compare it with GRACE TWS, the CLM4based TWS was calculated by summing canopy water, snow water equivalent, the vertical summation of liquid water and ice in all soil layers, water in the unconfined aquifers, and the water in rivers. The comparison of the two TWS anomalies estimates in Fig. 1 shows the overall consistency over time. The

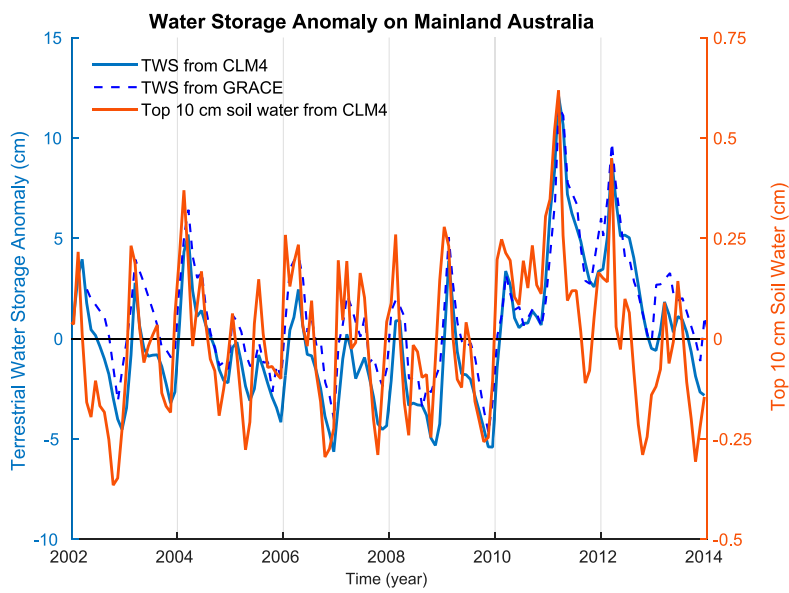

FIG. 1. Time series of water storage $(\mathrm{cm})$ over mainland Australia from GRACE observation (blue dashed line) and CLM4 (blue line) relative to the climatology from 2002 to 2013; the red line using the right axis shows the upper $10 \mathrm{~cm}$ soil water from CLM4.

CLM4-simulated TWS can capture not only the seasonal variability but also the interannual variations in GRACE. Australia was under the Millennium Drought from 1997 to 2010, and the gently declining trend in Fig. 1 also appears to be the impact of this decade-long drought. From 2003 to 2009, the TWS over mainland Australia decreased slightly as a recovery from the wet anomaly in 2000, which is consistent with Munier et al. (2012). The TWS then increased to a peak in 2011 and maintained a positive anomaly till 2012. The long persistence of water storage anomaly may result in an elevated level of ET during the corresponding period. In general, the seasonal cycle of ET can be captured well, when compared to the simulations from Global Land Evaporation Amsterdam Model (GLEAM; Martens et al. 2017; Miralles et al. 2011), the Australian Landscape Water Balance model (AWRA-L v6; Frost et al. 2018), and FLUXNET (Jung et al. 2009, 2011), with some discrepancies at the peak values as shown in Figs. S3-S5. The flux station data usually contain some extreme values, which are not shown in the gridded products or CLM simulations. The seasonal cycle shows a similar phase in these datasets but with different peak months. FLUXNET shows the lowest ET comparison, and the CLM4 simulation is close to the value of the station data. We also evaluated the ET at a more extended time period and larger area by comparing it to gridded datasets of GLDAS, FLUXNET, and CMRSET (CSIRO MODIS Reflectance-based Scaling ET). Figure S6 shows that observed ET from FLUXNET and CMRSET has smaller seasonal variations than LSM ET GLDAS averaged and CLM4. Nevertheless, all of the data show a large increase in ET in 2010/11.

Soil moisture at the top $10 \mathrm{~cm}$ increased during the flood event (Fig. 1), although it had a shorter persistence time than the TWS. CLM4-simulated $10 \mathrm{~cm}$ soil water and the resulting surface heat fluxes, including sensible heat and latent heat, are further employed to explore changes in the LCS. Volumetric 
soil water content (H2OSOI) comparison with the station data is shown in Figs. S7 and S8. Soil moisture increased since 2010 and peaked in early 2011. H2OSOI shows systematic bias between the station and grid data, but with similar temporal patterns.

\section{c. Land surface coupling index}

A land surface coupling index (LCI) proposed by Dirmeyer (2011) is used here to diagnose the LCS. This index can measure the sensitivity of surface flux to soil moisture variability. It can be described as follows:

$$
I_{\varphi}=S_{w} \times \beta_{\varphi} .
$$

The index $(I)$ is calculated from the slope $(\beta)$ of the linear fit from daily mean soil moisture $(w)$ to the land surface flux $(\varphi)$ (e.g., latent heat flux) and multiplied by the standard deviation of soil moisture $\left(S_{w}\right)$ for each month of all years. The averaged seasonal cycle is first removed for all the variables. In the original paper, the index is calculated from the daily soil moisture and surface flux in the same month of all years. To examine the interannual variability of the LCS, we derived the index for each month of each year. Note that the average value from each month is relatively close to the value calculated based on the original formulations of 50-yr daily data (Fig. S9). We calculated the LCI based on the top $10 \mathrm{~cm}$ soil moisture and latent heat flux, and the seasonal cycle is removed before calculating the index.

This index can determine the degree of LCS by "ET regimes" when the latent heat flux is regarded as the land surface flux $(\varphi)$. When the surface ET is soil moisture-limited, higher soil moisture would lead to increased ET, resulting in positive $\beta_{\varphi}$ and LCI. On the contrary, under an energy-limited condition, the LCI is expected to be close to zero or negative values since increased ET might lead to reduced soil moisture, and thus a negative $\beta_{\varphi}$.

While normal land-atmospheric coupling can be divided into the terrestrial segment and the atmospheric segment, the LCI of Eq. (1) only considers the terrestrial segment. The terrestrial segment refers to the relationship between conditions of the land surface (e.g., soil moisture) and land surface fluxes (e.g., latent and sensible heat fluxes); the atmospheric segment deals with the coupling of surface fluxes with planetary boundary layer processes and precipitation. Although Dirmeyer (2011) states that this index provides a "necessary but not sufficient condition", to indicate LCS, we assume that it is sufficient for us to distinguish the ET regimes during the entire analysis period. Furthermore, our offline CLM4 simulation does not couple the surface condition to the atmosphere, in which only the surface reflects atmospheric forcing, but the atmospheric condition would not be influenced by the surface condition. Thus, while a fully coupled landatmosphere model is outside the present study's scope, the coupled land-atmospheric modeling can be deployed in the future follow-up study to examine more detailed processes in the atmosphere triggered by the occasional large-scale flood inundation.

\section{Results}

The climatological precipitation of the AWAP data averaged over November-March from 1964 to 2013 is shown in Figs. 2a-e. During this season, the wet region presents in the northern part of Australia, but precipitation decreases sharply toward the south. Compared to the climatological mean of precipitation, the summer of 2010/11 shows a widespread positive anomaly in precipitation (Figs. $2 \mathrm{f}-\mathrm{j}$ ). Regions having climatological precipitation of 100 to $200 \mathrm{~mm} \mathrm{month}^{-1}$ at roughly $16^{\circ}$ to $21^{\circ} \mathrm{S}$ underwent a season of pronouncedly higher precipitation rate in 2010/11. The ET of this region, according to the positive LCI value in Figs. 3a-e, climatologically belongs to the soil moisture-limited regime. Such a region, however, may temporally shift into the transition section under a wetter condition. Due to the direct influence of precipitation on soil moisture, changes in LCI are expected to follow the anomalously large precipitation. In November and December 2010, the LCI remained high in the analyzed region enclosed by the blue box in Figs. $3 f$ and $3 g\left(16^{\circ}-21^{\circ} \mathrm{S}, 125^{\circ}-145^{\circ} \mathrm{E}\right)$. This suggests that the soil moisture and ET still maintained a positive relationship during the period. However, from January to March 2011, the LCI dropped to anomalously low values with the northern part of the analysis region having negative values (Figs. 3h-j). Hydrometeorological processes responsible for the negative relationship between precipitation and LCI during the second half of the event can be inferred by examining their temporal variation. The following results are based on the mean condition in the blue box in Figs. $3 \mathrm{f}-\mathrm{j}$.

To examine the variability of LCS during the flood, the anomaly time series of LCI, precipitation, latent heat flux, sensible heat flux, and top $10 \mathrm{~cm}$ soil water averaged in the analyzed region are compared (Fig. 4). Beginning in September, the fluctuation in latent heat flux follows the soil moisture, and the increasing trend can be seen in both soil water and latent heat flux. However, after December 2010, despite the increase in soil moisture owing to the accumulated heavy rain, the latent heat flux approached saturation and hardly increased with soil moisture, which resulted in a decline in LCI. This corresponds to the transition of LCI from positive in 2010 to near-zero and negative values in 2011 (Figs. 3f-j). Besides latent heat flux, Fig. $4 \mathrm{~b}$ further shows the change in sensible heat flux. Since the latent heat flux anomaly kept increasing since November 2010, there was a decline in the anomaly of sensible heat flux until April 2011. This indicates an altered Bowen ratio due to the wetter soil. However, the available energy is not enough to enable the variation of latent heat flux to cohere with soil moisture, resulting in the shifting of the ET condition toward the energy-limited regime.

Besides the relative variation of the anomalous soil moisture and the anomalous latent heat flux, the absolute values and the climatology further support our conjecture. The open circles in Fig. 5 show the climatological relationship between the upper $10 \mathrm{~cm}$ soil moisture content and latent heat flux. As soil moisture is the constraining factor for ET in semiarid regions, the latent heat flux generally has a positive linear relationship with the upper layer soil water. However, it becomes irregular during the flooding period as shown by the solid circles in 

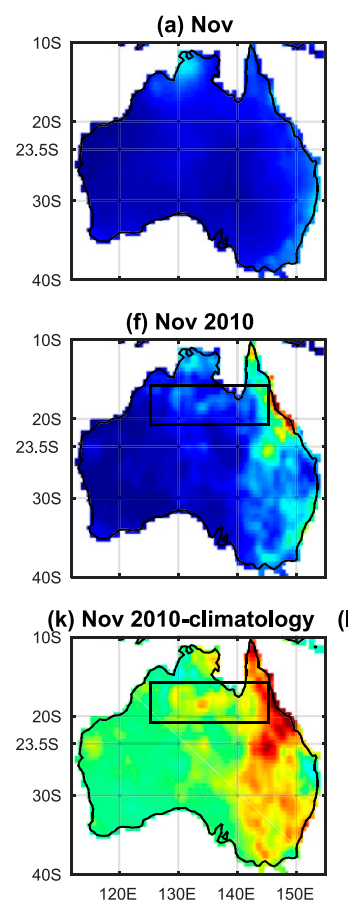

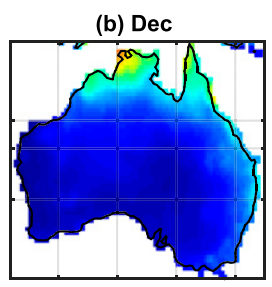

(g) Dec 2010

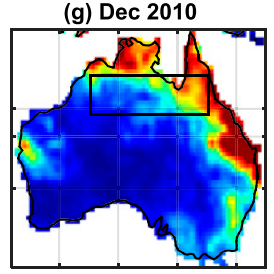

.

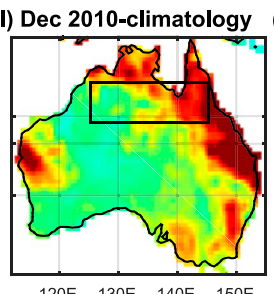

(c) Jan

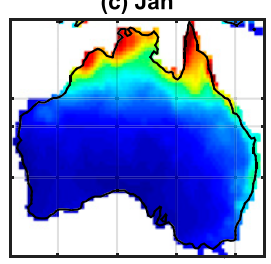

(h) Jan 2011

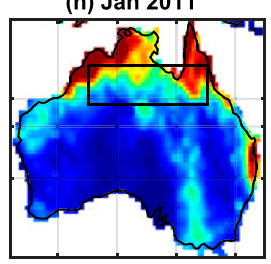

(m) Jan 2011-climatology

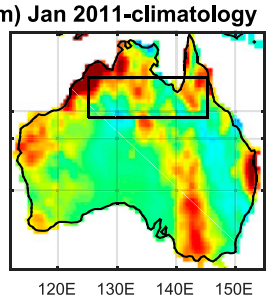

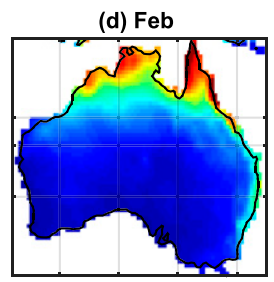

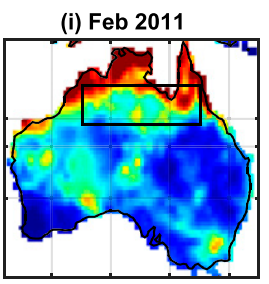

(n) Feb 2011-climatology

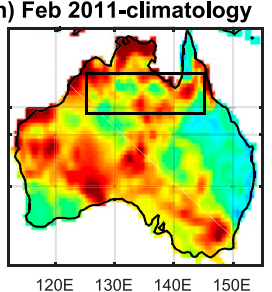

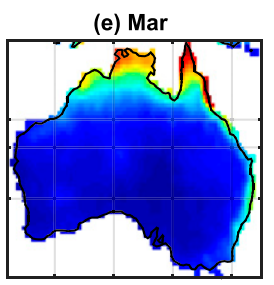

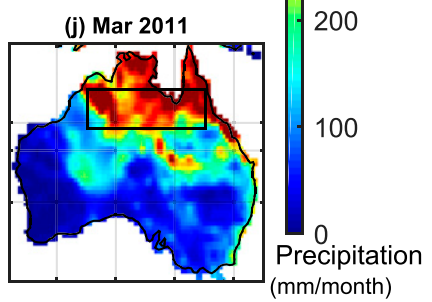

(o) Mar 2011-climatology

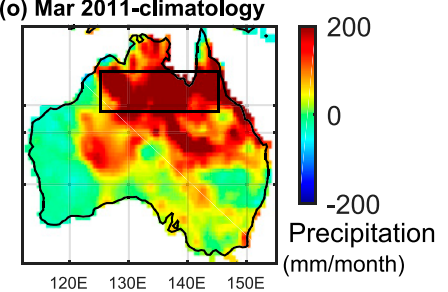

FIG. 2. (a)-(e) The 1964 to 2013 AWAP climatological precipitation (mm month ${ }^{-1}$ ) from November to March, respectively.(f)-(j) Precipitation (mm month ${ }^{-1}$ ) from November 2010 to March 2011, respectively. (k)-(o) Precipitation difference of November 2010 to March 2011 [in (f)-(j)] minus its climatology [in (a)-(e)]. Black boxes in (f)-(o) indicate the region following figures focus on.

Fig. 5. When the upper $10 \mathrm{~cm}$ soil water increases over 20-25 mm, the latent heat flux starts leveling off and slightly declining with the further increase of soil moisture. This suggests the transition of ET conditions from the soil moisturelimited regime toward the energy-limited regime when this region undergoes the flood. If this is the case, the signal will also present in the relationship between LCI and soil moisture.

Figure 6a shows the 1-yr running mean of upper $10 \mathrm{~cm}$ soil water and the LCI from monthly data. In early 2010, LCI and soil water had a positive relationship: the LCI increased with the increment of soil moisture. However, when soil moisture became more than approximately $18 \mathrm{~mm}$ in the middle of 2010 , the LCI no longer followed the upward trend with the soil moisture. The LCI became low and did not recover until the middle of 2011. Consistently, the variations can also be found when comparing the original monthly data to the climatology (Fig. 6b). At the beginning of the event, the heavy rain led to a high LCI anomaly. Soon after December 2010, the LCI fell far below the climatology and met the lowest point in March 2011, with a value of nearly 0 . This low value is not seen in Fig. 6a because of the smoothing. After March, the LCI gradually climbed back. Figure 6 as a whole indicated that when the flood event occurred in this region, the sensitivity of ET to soil moisture became higher at first. After the soil moisture reached a certain degree, the sensitivity, or LCI, declined until the soil moisture decreased again. The hysteresis pattern could also be found in climatological values but exacerbated during this flooding year.
As the LCI can be separated into two components, $S_{w}$ and $\beta_{\varphi}$, Fig. 7 is plotted to discuss the reason for changes in LCI in Fig. 6b. The variation of soil moisture $\left(S_{w}\right)$ remained high and became even higher as the soil moisture increases. The decrease in LCI was mainly due to the decrease in $\beta_{\varphi}$, namely the linear regression slope of the soil moisture and ET. Note that the $x$ axes of Figs. 5 and 7 are comparable. Whereas the LCI declines when the soil gets wetter (Fig. 7), the latent heat flux increases with soil moisture until it approaches saturation (Fig. 5). This is similar to Fig. 2 in Koster et al. (2004). In their study, the low soil moisture condition with low ET and high diagnostic index indicates the soil moisture-limited regime; the low diagnostic index and high soil moisture condition with high ET hardly increase with soil moisture, indicating the energy-limited regime. Applying this to our study area, northern Australia, which is originally under the soil moisture-limited regime during this season, is suggested to undergo the transition regime when floods occur.

\section{Discussion}

Our study shows the potential of a shifting surface condition during a hydrological event in 2010/11. The thresholds of surface soil moisture between different phases are worth discussing since the phases determine the LCS. Besides, for a hydrological event, a factor in determining the degree and temporal duration of the influence is the soil moisture memory, which is also a spatial dependent property.

As land surface generally evolves more slowly than the atmosphere, it is a source of extended memory for subseasonal to 

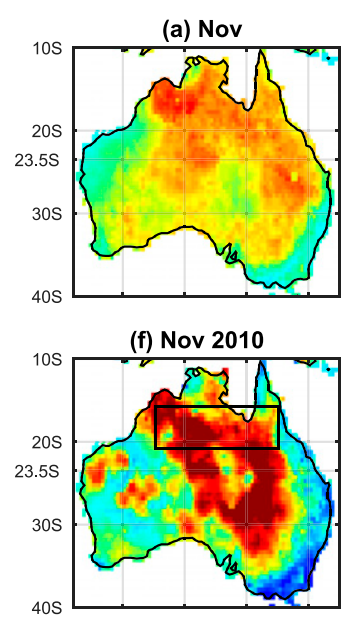

(k) Nov 2010-climatology

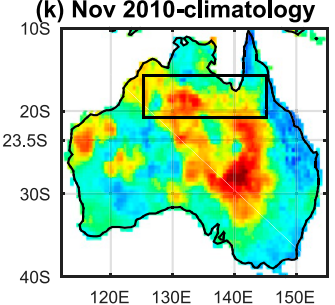

(b) Dec

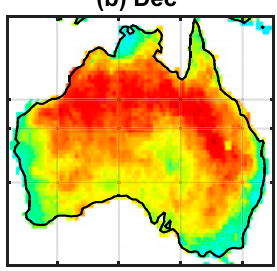

(g) Dec 2010

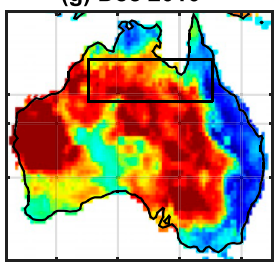

(c) Jan

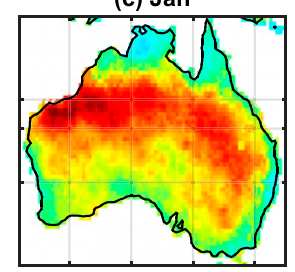

(h) Jan 2011

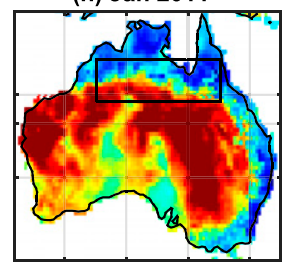

(d) Feb

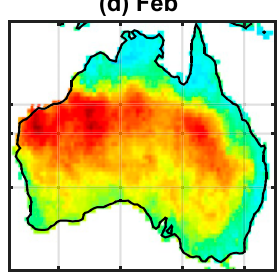

(i) Feb 2011

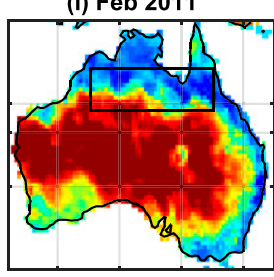

(e) Mar
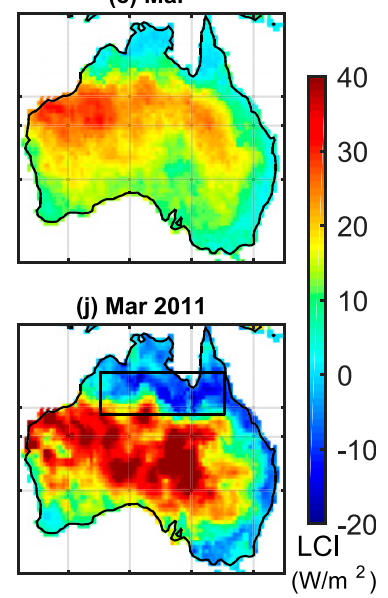

(I) Dec 2010-climatology
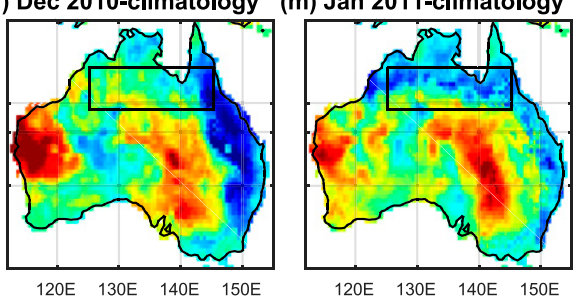

(n) Feb 2011-climatology

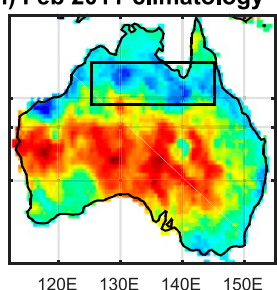

(o) Mar 2011-climatology

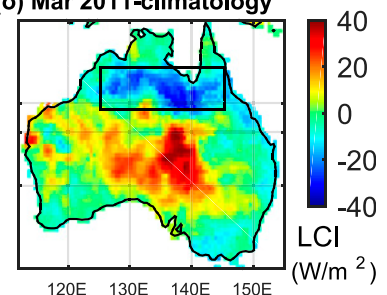

FIG. 3. As in Fig. 2, but with LCI $\left(\mathrm{W} \mathrm{m}^{-2}\right)$ calculated from CLM4 simulation; the black boxes in (f)-(o) indicate the region the following figures focus on.

seasonal predictions. Unlike for a weather forecast, which depends on the atmospheric initial conditions, land and ocean initial conditions such as sea surface temperature and soil moisture content are essential for subseasonal to seasonal forecasting systems (Pegion et al. 2019). Uncovering the relationship between the surface condition and surface fluxes is crucial for the improvement of numerical modeling. Previous studies have shown biases of ET existing in the land surface model (Swenson and Lawrence 2014) and pointed out the importance of soil moisture for weather and climate prediction (Dirmeyer and Halder 2016). Koster et al. (2004) also suggested that in regions with surface characteristics in the transition section, soil moisture could influence precipitation. Thus, taking the surface condition of those regions into account is crucial for subseasonal to seasonal climate prediction.

As a region may transit from a soil moisture-limited to the transition section and energy-limited regime during a hydrological event, taking changes in surface condition due to such events into consideration might also impact the results of numerical prediction. However, more numerical experiments are necessary to address this perspective. Here, we did two additional sets of analyses to demonstrate the robustness of our results. First of all, previous studies have mentioned the importance of root-zone soil moisture (SM) contributions to transpiration fraction change and a good rank relationship to the lifted condensation level (Decker et al. 2015). While the study only discussed transpiration, we consider the total evaporation to be a factor of the near-surface atmospheric state, which is directly affected by the surface SM. The overarching goal of this study is to represent LCS and show the LCI-SM phase's outlier status during a prolonged wet period. We further analyzed the root-zone soil moisture to support the results (Fig. S10). The phase diagram using root-zone SM (Fig. S10) shows a similar performance to the results from using
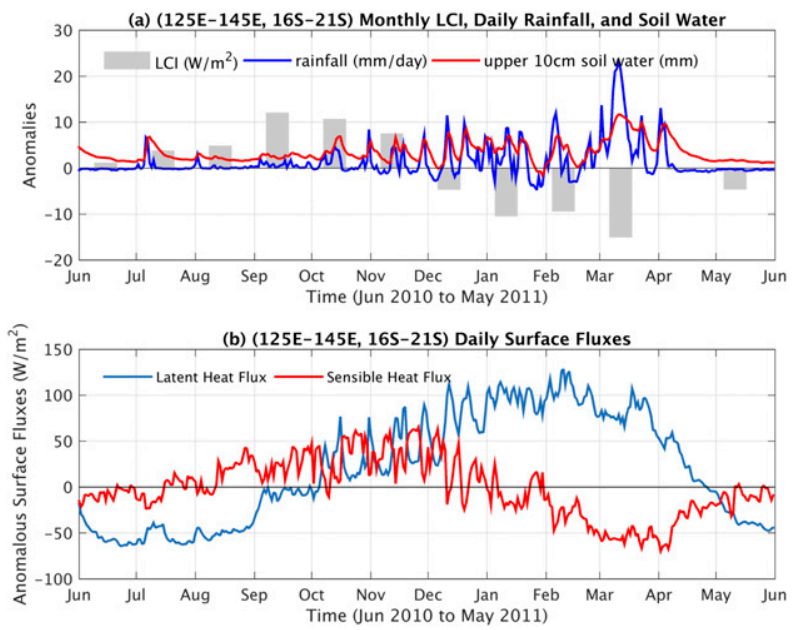

FIG. 4. Time series of (a) daily rainfall $\left(\mathrm{mm} \mathrm{day}^{-1}\right)$, upper $10 \mathrm{~cm}$ soil water $(\mathrm{mm})$, and monthly LCI $\left(\mathrm{W} \mathrm{m}^{-2}\right)$ and $(\mathrm{b})$ latent heat flux $\left(\mathrm{W} \mathrm{m}^{-2}\right)$ and sensible heat flux $\left(\mathrm{W} \mathrm{m}^{-2}\right)$ area averaged in the black box of Fig. 2 relative to the climatology from 1964 to 2013. 


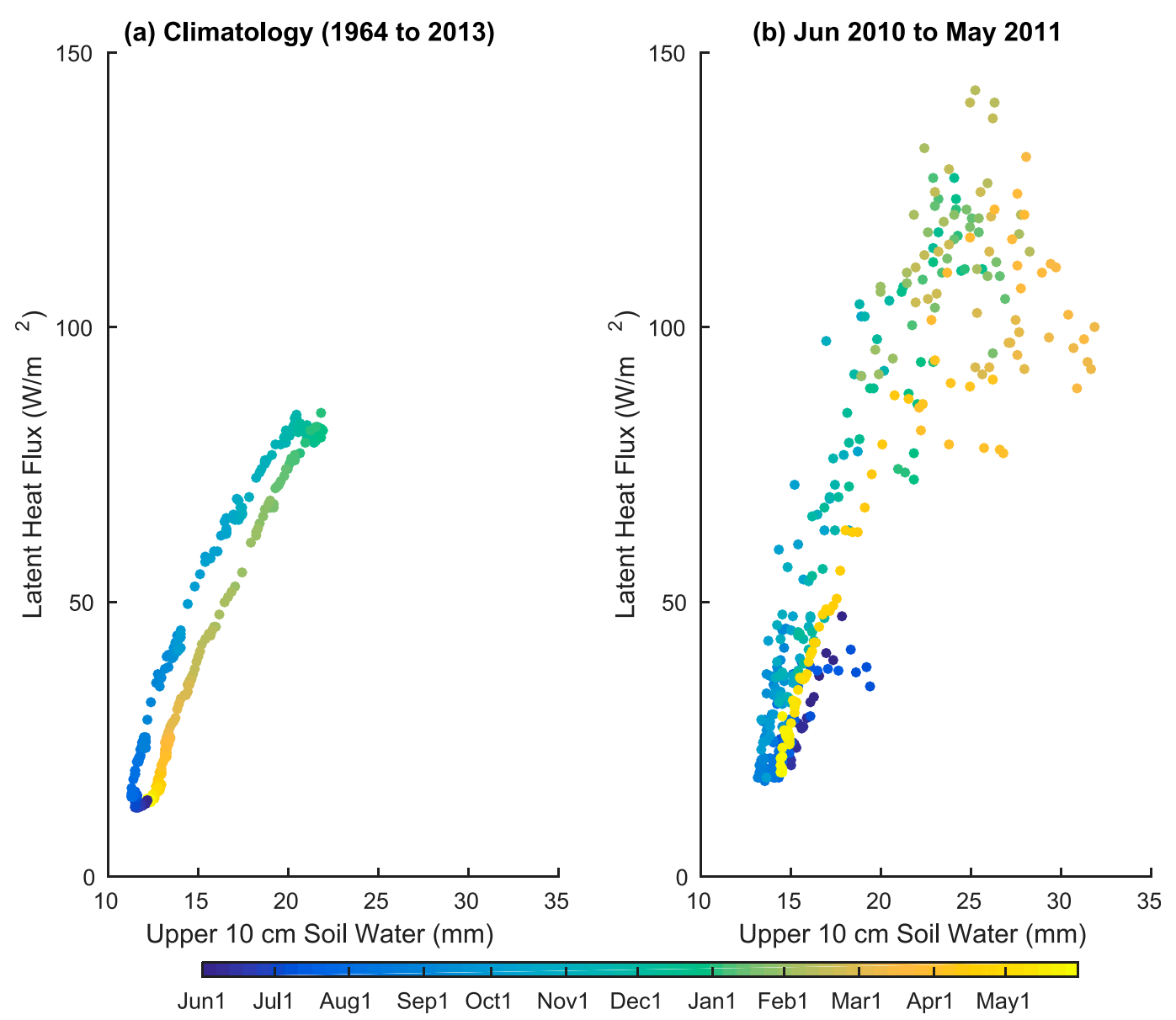

FIG. 5. (a) Scatterplot of climatological and (b) 2010/11 daily upper $10 \mathrm{~cm}$ soil water (mm) and latent heat flux $\left(\mathrm{W} \mathrm{m}^{-2}\right)$ in the black box of Fig. 2 .

$10 \mathrm{~cm} \mathrm{SM}$ as given Fig. 6b. Second, comparing the 2010/11 case we focus on with previous flooding events in 1974 and 2000, similar changes in phases of the LCI-SM relationship are observed (Figs. S11 and S12). This indicates that the weakening of LCI could be a common feature during extreme flooding compared to the climatological condition. It also implies that the linkage between soil moisture and latent heat flux is decoupled temporarily during the flooding events, which might further impact the boundary layer development and the land-atmosphere coupling.

In addition to SM, other factors such as net radiation, atmospheric water vapor deficit, wind, and vegetation can affect ET as indicated by a decline in SM-ET coupling (LCS). For example, Fig. 5 shows that the decreased LCS is associated with more tendency toward an energy-limited regime, indicating that ET is less dominated by $\mathrm{SM}$ in the middle to the late stage of flooding. Figure S13 shows that the net radiation and latent heat fluxes reached their maximum in January/February and decreased. Due to wetter soil and greening (Fig. S14), the net radiation and ET in the 2010/11 warm season are continuously higher than the average. In this semiarid region, flooding leads to a greener landscape (Bastos et al. 2013; Poulter et al. 2014). In addition to stomatal conductance, increasing vegetation might be dominant and cause increased transpiration.

Memory or persistence of anomaly in land surface states is a necessary condition for the land surface to significantly influence the atmosphere. Here we show the variability in land surface states and the surface flux sensitivity to the land surface wetness using the LCS. Changes in surface fluxes directly affect atmospheric conditions. Sensible heat flux controls the planetary boundary layer's growth and the stability of the nearsurface atmosphere, and latent heat flux contributes to the humidity in the boundary layer. These fluxes, thus, influence the occurrence of convective precipitation as illustrated in previous studies (e.g., Yin et al. 2015; Dirmeyer et al. 2019). The flooding event discussed here led to changes in the Bowen ratio (Fig. 4), which may also influence convective precipitation initiation. Convection may be triggered under certain conditions. For example, when the planetary boundary layer height crosses the lifted condensation level (LCL crossing) and sufficient convective available potential energy (CAPE) is available (Yin et al. 2015). While both wet and dry land surfaces can lead to LCL crossing, the moist land surface is 

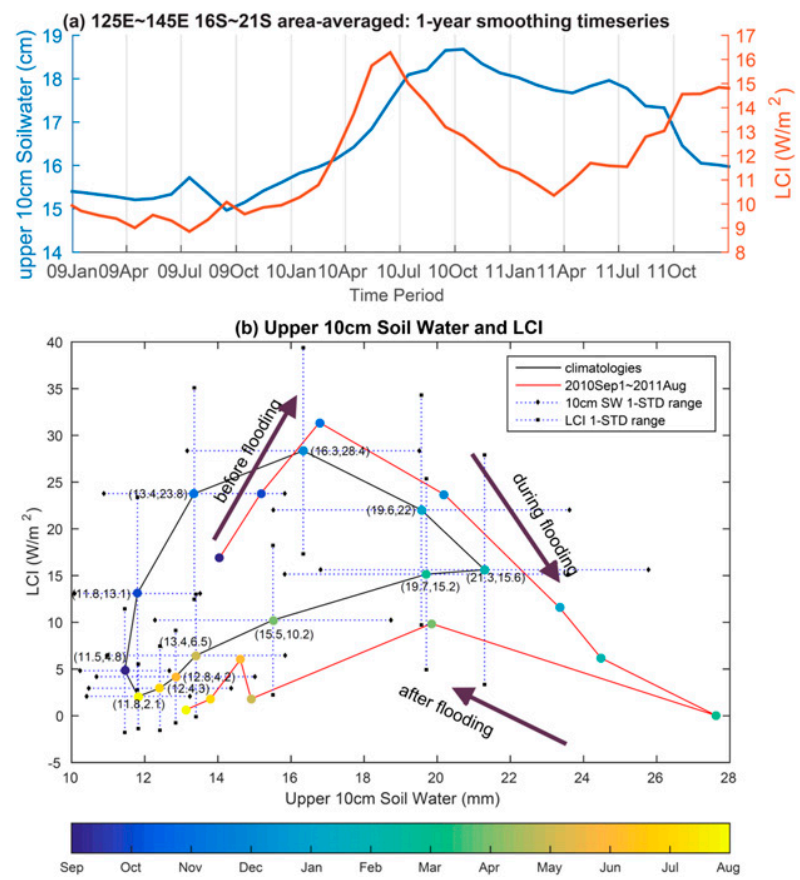

FIG. 6. (a) The 1-yr running mean of monthly upper $10 \mathrm{~cm}$ soil water $(\mathrm{mm})$ and LCI $\left(\mathrm{W} \mathrm{m}^{-2}\right)$ from 2009-11. (b) Scatterplot of monthly upper $10 \mathrm{~cm}$ soil water $(\mathrm{mm})$ and LCI $\left(\mathrm{W} \mathrm{m}^{-2}\right)$ in the box. Points connected with the black line show the climatology and points connected with the red line show the data in 2010/11; the coordinate values $(x, y)$ next to the black line are the climatology soil water $(x)$ and climatology LCI $(y)$ for each month. The dashed line with the square mark is the LCI \pm 1 standard deviation (STD) range, while the dashed line with a diamond mark is $10 \mathrm{~cm}$ soil moisture \pm 1 STD range.

favorable for the existence of large CAPE (Yin et al. 2015). Thus, the land surface's wetness can control the initiation and intensity of precipitation when there is an effective land surface coupling.

While studies exist that discuss the soil moisture effect on atmospheric state and its application on subseasonal to seasonal forecasts, our study focuses on a different season on a longer time scale. Having the spatial domain over Australia, Zhao et al. (2019) recently proved the impact of soil moisture memory on the subseasonal to seasonal forecast during the cold season (May-July). However, the forecasting ability in other seasons has not been discussed yet. Some studies have explored the relationship between SM and rainfall on a daily time scale. For example, Hsu et al. (2017) explored the relationship between SM in the morning and the rainfall in the afternoon and show that rainfall is more likely over very wet areas, and Holgate et al. (2019) explored the relationship between today's SM and the next day's rainfall and found significant positive soil moisture-rainfall correlations in northern and arid central Australia during the wet seasons. Both of these two studies focus on the SM-precipitation relationship on time scales of the day; on the contrary, our study-based on the LCI definition in Dirmeyer (2011) - focuses on the monthly

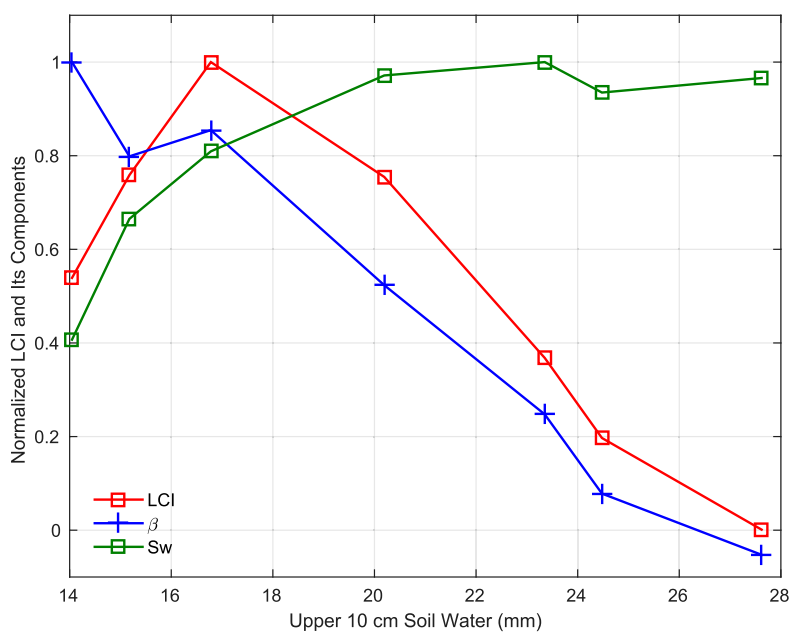

FIG. 7. Changes in monthly LCI and its components normalized by the maximum value of data during September 2010 to March 2011 (before and during flooding).

variation of soil moisture-rainfall coupling using the regression coefficients between daily soil moisture and rainfall within a month and, further, explores its interannual variations.

Our analysis-including 1) the land surface coupling strength, 2) variability in land surface states, and 3) persistence of surface state anomaly-provides important insight into the role of land surface into subseasonal to seasonal predictions. While a few examples of operational land surface data assimilation existed previously (Barbu et al. 2014; Balsamo et al. 2015; Gustafsson et al. 2018), some systems do not assimilate actual land surface observations and rather rely on assimilating meteorological data (Dirmeyer et al. 2019). Although testing the subseasonal to seasonal predictability might be out of our work's scope, this study suggests the importance of considering significant and persisting anomalies in land surface states when making subseasonal to seasonal predictions. In addition, while this study uses CLM4 to explore the LCI changes, results from the updated CLM (i.e., CLM4.5) also indicate the altered LCI under the 2010/11 flooding events. In the future, CLM5 coupled with the atmosphere model can be considered to explore further how it feeds back to the atmosphere. We further calculate the phase diagram of LCS changes using the ERA5 dataset (Fig. S15), which has similar patterns to those shown in Fig. 6 from offline CLM simulations, indicating that such LCS changes can exist in other datasets.

\section{Summary}

In previous studies, among the three phases of ET condition, the transition section is the one that soil moisture would mostly influence the atmospheric conditions, including precipitation. Most of the previous studies discussed the hot spots of landatmosphere coupling on a spatial basis (Koster et al. 2004; Guo et al. 2006). The hot spots of LCS are mainly over semiarid regions, a transition zone between the humid and arid climate with ET condition being in the transition section. Some of the 
studies further discussed the interannual and seasonal variability (Dirmeyer 2011; Guo and Dirmeyer 2013). Those studies suggested the change of dry and wet regions into different phases of ET conditions under certain situations. For example, a soil moisture-limited region such as Australia might shift into the transition section when it is anomalously wet (flooding event in 2010/11). However, changes in surface conditions due to hydrological events (i.e., floods and droughts) have not been uncovered yet.

Here, we elucidate the mechanism of land-atmosphere coupling during an extreme flood event in northern Australia. From late 2010 to early 2011, Australia underwent an anomalously wet year due to the ENSO. The enhancement of precipitation especially presents in northern Australia (Fig. 2). Consistently, the GRACE data and our simulation by the CLM4 both indicate an increase in TWS for the whole of Australia (Fig. 1). As the ET condition is usually soil moisturelimited in the semiarid region in northern Australia, a positive correlation between soil moisture and ET is suspected. However, as the precipitation kept having a positive anomaly throughout the whole period, LCI had a negative anomaly in northern Australia $\left(16^{\circ}-21^{\circ} \mathrm{S}, 125^{\circ}-145^{\circ} \mathrm{E}\right)$ in 2011 . As the positive LCI indicates a soil moisture-limited condition, and negative or near-zero LCI indicates an energy-limited one, the result implies the alteration of surface ET condition.

An insight into changes in the surface during the flood is gained through further exploring the temporary change in the LCI (Figs. 4 and 6). In the beginning, the trend in LCI consists of the increase in surface soil moisture, which indicates the soil moisture-limited condition of the region. However, from November 2010 to March 2011, despite the continuous rise in the upper $10 \mathrm{~cm}$ soil moisture, the LCI kept declining and nearly approached zero in March 2011. The LCI was anomalously low and suggests altering surface conditions from a soil moisture-limited to the transition section. Figures 5 and 7, in combination, further support our perspective. As the soil moisture increased, the LCI declined by lowering the linear increase in ET rate with soil moisture. Thus, in some specific regions of the world, if the land-atmosphere coupling can change from the soil moisture-limited regime to an energylimited regime, LCS temporal variations (such as in the phase diagram in Fig. 6) should exist. Such temporal variation of the LCS has essential applications for realistic parameterization of the land-atmosphere coupling in climate models and consequently improving subseasonal to seasonal climate forecast.

Acknowledgments. This study is supported by the Ministry of Science and Technology in Taiwan under Grants 106-2111M-002-010-MY4 and 107-2111-M-002-001-MY3. GRACE/ GRACE-FO Mascon data are available at http://grace.jpl. nasa.gov. Global Land Data Assimilation System datasets are obtained from https://das.gsfc.nasa.gov/gldas. The Australian precipitation is obtained from the Australian Water Availability Project (AWAP; Jones et al. 2009; Raupach et al. 2009, 2012). We thank all the scientists, software engineers, and administrators who contributed to the development of CESM. Part of the content is based on the second author Wen-Ying Wu's master thesis at the Department of Atmospheric Sciences, National Taiwan University in 2015.

\section{REFERENCES}

Balsamo, G., and Coauthors, 2015: ERA-Interim/Land: A global land surface reanalysis data set. Hydrol. Earth Syst. Sci., 19, 389-407, https://doi.org/10.5194/hess-19-389-2015.

Barbu, A. L., J. C. Calvet, J. F. Mahfouf, and S. Lafont, 2014: Integrating ASCAT surface soil moisture and GEOV1 leaf area index into the SURFEX modelling platform: A land data assimilation application over France. Hydrol. Earth Syst. Sci., 18, 173-192, https://doi.org/10.5194/hess-18-173-2014.

Basara, J. B., and J. I. Christian, 2018: Seasonal and interannual variability of land-atmosphere coupling across the southern Great Plains of North America using the North American Regional Reanalysis. Int. J. Climatol., 38, 964-978, https:// doi.org/10.1002/joc.5223.

Bastos, A., S. W. Running, C. Gouveia, and R. M. Trigo, 2013: The global NPP dependence on ENSO: La Niña and the extraordinary year of 2011. J. Geophys. Res. Biogeosci., 118, 12471255, https://doi.org/10.1002/jgrg.20100.

Boening, C., J. K. Willis, F. W. Landerer, R. S. Nerem, and J. Fasullo, 2012: The 2011 La Niña: So strong, the oceans fell. Geophys. Res. Lett., 39, L19602, https://doi.org/10.1029/ 2012 GL053055.

Budyko, M. I., 1974: Climate and Life. Academic Press, 508 pp.

Chambers, D. P., J. Wahr, and R. S. Nerem, 2004: Preliminary observations of global ocean mass variations with GRACE. Geophys. Res. Lett., 31, L13310, https://doi.org/10.1029/2004 GL020461.

Chen, F., and Y. Zhang, 2009: On the coupling strength between the land surface and the atmosphere: From viewpoint of surface exchange coefficients. Geophys. Res. Lett., 36, L10404, https://doi.org/10.1029/2009GL037980.

Cheruy, F., A. Campoy, J.-C. Dupont, A. Ducharne, F. Hourdin, M. Haeffelin, M. Chiriaco, and A. Idelkadi, 2013: Combined influence of atmospheric physics and soil hydrology on the simulated meteorology at the SIRTA atmospheric observatory. Climate Dyn., 40, 2251-2269, https://doi.org/10.1007/ s00382-012-1469-y.

Chou, C., D. Ryu, M.-H. Lo, H. Wey, and H. Malano, 2018: Irrigation induced land-atmosphere feedback and their impacts on Indian summer monsoon. J. Climate, 31, 8785-8801, https://doi.org/10.1175/JCLI-D-17-0762.1.

Costelloe, J. F., R. B. Grayson, R. M. Argent, and T. A. McMahon, 2003: Modelling the flow regime of an arid zone floodplain river, Diamantina River, Australia. Environ. Modell. Software, 18, 693-703, https://doi.org/10.1016/S13648152(03)00071-9.

Dahle, C., F. Flechtner, C. Gruber, D. König, R. König, G. Michalak, and K.-H. Neumayer, 2012: GFZ GRACE Level-2 Processing Standards Document for Level-2 Product Release 0005, Scientific Tech. Rep. STR12/02, Potsdam, 21 pp., https://doi.org/10.2312/GFZ.b103-1202-25.

Decker, M., A. Pitman, and J. Evans, 2015: Diagnosing the seasonal land-atmosphere correspondence over northern Australia: Dependence on soil moisture state and correspondence strength definition. Hydrol. Earth Syst. Sci., 19, 34333447, https://doi.org/10.5194/hess-19-3433-2015.

Dirmeyer, P. A., 2011: The terrestrial segment of soil moistureclimate coupling. Geophys. Res. Lett., 38, L16702, https:// doi.org/10.1029/2011GL048268.

, and S. Halder, 2016: Sensitivity of numerical weather forecasts to initial soil moisture variations in CFSv2. Wea. Forecasting, 31, 1973-1983, https://doi.org/10.1175/WAF-D16-0049.1. 
— R. R. Koster, and Z. Guo, 2006: Do global models properly represent the feedback between land and atmosphere? J. Hydrometeor., 7, 1177-1198, https://doi.org/10.1175/JHM532.1. —, S. Kumar, M. J. Fennessy, E. L. Altshuler, T. DelSole, Z. Guo, B. A. Cash, and D. Straus, 2013: Model estimates of land-driven predictability in a changing climate from CCSM4. J. Climate, 26, 8495-8512, https://doi.org/10.1175/JCLI-D-1300029.1.

_- P. Gentine, M. B. Ek, and G. Balsamo, 2019: Land surface processes relevant to sub-seasonal to seasonal (S2S) prediction. Sub-Seasonal to Seasonal Prediction, A. W. Robertson and F. Vitart, Eds., Elsevier, 165-181.

Eltahir, E. A., 1998: A soil moisture-rainfall feedback mechanism: 1. Theory and observations. Water Resour. Res., 34, 765-776, https://doi.org/10.1029/97WR03499.

Entekhabi, D., I. Rodriguez-Iturbe, and F. Castelli, 1996: Mutual interaction of soil moisture state and atmospheric processes. J. Hydrol., 184, 3-17, https://doi.org/10.1016/0022-1694(95) 02965-6.

Fasullo, J. T., C. Boening, F. W. Landerer, and R. S. Nerem, 2013: Australia's unique influence on global sea level in 2010-2011. Geophys. Res. Lett., 40, 4368-4373, https://doi.org/10.1002/ grl.50834.

Findell, K. L., and E. A. Eltahir, 1997: An analysis of the soil moisture-rainfall feedback, based on direct observations from Illinois. Water Resour. Res., 33, 725-735, https://doi.org/ 10.1029/96WR03756.

Frost, A. J., A. Ramchurn, and A. Smith, 2018: The Australian Landscape Water Balance model (AWRA-L v6). Technical Description of the Australian Water Resources Assessment Landscape model version 6, Bureau of Meteorology Tech. Rep., 58 pp.

Guillod, B. P., B. Orlowsky, D. G. Miralles, A. J. Teuling, and S. I. Seneviratne, 2015: Reconciling spatial and temporal soil moisture effects on afternoon rainfall. Nat. Commun., 6, 6443, https://doi.org/10.1038/ncomms7443.

Guo, Z., and P. A. Dirmeyer, 2013: Interannual variability of landatmosphere coupling strength. J. Hydrometeor., 14, 16361646, https://doi.org/10.1175/JHM-D-12-0171.1.

— , and Coauthors, 2006: GLACE: The Global Land-Atmosphere Coupling Experiment. Part II: Analysis. J. Hydrometeor., 7, 611-625, https://doi.org/10.1175/JHM511.1.

Gustafsson, N., and Coauthors, 2018: Survey of data assimilation methods for convective-scale numerical weather prediction at operational centres. Quart. J. Roy. Meteor. Soc., 144, 12181256, https://doi.org/10.1002/qj.3179.

Hohenegger, C., P. Brockhaus, C. S. Bretherton, and C. Schär, 2009: The soil moisture-precipitation feedback in simulations with explicit and parameterized convection. J. Climate, 22, 5003-5020, https://doi.org/10.1175/2009JCLI2604.1.

Holgate, C., A. Van Dijk, J. Evans, and A. Pitman, 2019: The importance of the one-dimensional assumption in soil moisture-rainfall depth correlation at varying spatial scales. J. Geophys. Res. Atmos., 124, 2964-2975, https://doi.org/10.1029/2018JD029762.

Hsu, H., M. H. Lo, B. P. Guillod, D. G. Miralles, and S. Kumar, 2017: Relation between precipitation location and antecedent/ subsequent soil moisture spatial patterns. J. Geophys. Res. Atmos., 122, 6319-6328, https://doi.org/10.1002/2016JD026042.

Hurrell, J. W., and Coauthors, 2013: The Community Earth System Model: A framework for collaborative research. Bull. Amer. Meteor. Soc., 94, 1339-1360, https://doi.org/10.1175/BAMS-D-12-00121.1.

Jarihani, A. A., J. R. Larsen, J. N. Callow, T. R. McVicar, and K. Johansen, 2015: Where does all the water go? Partitioning water transmission losses in a data-sparse, multi-channel and low-gradient dryland river system using modelling and remote sensing. J. Hydrol., 529, 1511-1529, https://doi.org/10.1016/ j.jhydrol.2015.08.030.

Jones, D. A., W. Wang, and R. Fawcett, 2009: High-quality spatial climate data-sets for Australia. Aust. Meteor. Oceanogr. J., 58, 233-248, https://doi.org/10.22499/2.5804.003.

Jung, M., M. Reichstein, and A. Bondeau, 2009: Towards global empirical upscaling of FLUXNET eddy covariance observations: Validation of a model tree ensemble approach using a biosphere model. Biogeosciences, 6, 2001-2013, https://doi.org/ 10.5194/bg-6-2001-2009.

_ , and Coauthors, 2011: Global patterns of land-atmosphere fluxes of carbon dioxide, latent heat, and sensible heat derived from eddy covariance, satellite, and meteorological observations. J. Geophys. Res., 116, G00J07, https://doi.org/10.1029/ 2010JG0566.

Koster, R. D., M. J. Suarez, and M. Heiser, 2000: Variance and predictability of precipitation at seasonal-to-interannual timescales. J. Hydrometeor., 1, 26-46, https://doi.org/10.1175/15257541(2000)001<0026:VAPOPA > 2.0.CO;2.

$\longrightarrow,-$, R. W. Higgins, and H. M. van den Dool, 2003: Observational evidence that soil moisture variations affect precipitation. Geophys. Res. Lett., 30, 1241, https://doi.org/ 10.1029/2002GL016571.

- , and Coauthors, 2004: Regions of strong coupling between soil moisture and precipitation. Science, 305, 1138-1140, https:// doi.org/10.1126/science.1100217.

- and Coauthors, 2010: Contribution of land surface initialization to subseasonal forecast skill: First results from a multimodel experiment. Geophys. Res. Lett., 37, L02402, https:// doi.org/10.1029/2009GL041677.

Lawrence, D. M., and Coauthors, 2011: Parameterization improvements and functional and structural advances in version 4 of the Community Land Model. J. Adv. Model. Earth Syst., 3, M03001, https://doi.org/10.1029/2011MS00045.

Lo, M. H., and J. S. Famiglietti, 2010: Effect of water table dynamics on land surface hydrologic memory. J. Geophys. Res., 115, D22118, https://doi.org/10.1029/2010JD014191.

— strengthens the southwestern US water cycle. Geophys. Res. Lett., 40, 301-306, https://doi.org/10.1002/grl.50108.

Martens, B., and Coauthors, 2017: GLEAM v3: Satellite-based land evaporation and root-zone soil moisture. Geosci. Model Dev., 10, 1903-1925, https://doi.org/10.5194/gmd-10-1903-2017.

McMahon, T. A., R. E. Murphy, M. C. Peel, J. F. Costelloe, and F. H. S. Chiew, 2008: Understanding the surface hydrology of the Lake Eyre Basin: Part II-Streamflow. J. Arid Environ., 72, 1869-1886, https://doi.org/10.1016/j.jaridenv.2008.06.001.

Miralles, D. G., T. R. H. Holmes, R. A. M. de Jeu, J. H. Gash, A. G. C. A. Meesters, and A. J. Dolman, 2011: Global landsurface evaporation estimated from satellite-based observations. Hydrol. Earth Syst. Sci., 15, 453-469, https://doi.org/ 10.5194/hess-15-453-2011.

Munier, S., M. Becker, P. Maisongrande, and A. Cazenave, 2012: Using GRACE to detect groundwater storage variations: The cases of Canning basin and Guarani aquifer system. Int. Water Technol. J., 2, 2-13, https://hal.archives-ouvertes.fr/ hal-01162472.

Oleson, K. W., and Coauthors, 2010: Technical description of version 4.0 of the Community Land Model (CLM). NCAR Tech. Note NCAR/TN-478+STR, 257 pp., https://doi.org/ 10.5065/D6FB50WZ. 
Pegion, K., and Coauthors, 2019: The Subseasonal Experiment (SubX): A multimodel subseasonal prediction experiment. Bull. Amer. Meteor. Soc., 100, 2043-2060, https://doi.org/ 10.1175/BAMS-D-18-0270.1.

Poulter, B., and Coauthors, 2014: Contribution of semi-arid ecosystems to interannual variability of the global carbon cycle. Nature, 509, 600-603, https://doi.org/10.1038/nature13376.

Ramillien, G., A. Cazenave, and O. Brunau, 2004: Global time variations of hydrological signals from GRACE satellite gravimetry. Geophys. J. Int., 158, 813-826, https://doi.org/10.1111/ j.1365-246X.2004.02328.x.

Raupach, M. R., P. R. Briggs, V. Haverd, E. A. King, M. Paget, and C. M. Trudinger, 2009: Australian Water Availability Project (AWAP): CSIRO Marine and Atmospheric Research Component: Final Report for Phase 3. CAWCR Tech. Rep. 013, $67 \mathrm{pp}$.

$-,-,-\longrightarrow,-$, and,- 2012: Australian Water Availability Project. CSIRO Marine and Atmospheric Research, accessed 2 March 2015, http://www.csiro.au/awap.

Rodell, M., and Coauthors, 2004a: The Global Land Data Assimilation System. Bull. Amer. Meteor. Soc., 85, 381-394, https://doi.org/ 10.1175/BAMS-85-3-381.

— J. S. Famiglietti, J. Chen, S. I. Seneviratne, P. Viterbo, S. Holl, and C. R. Wilson, 2004b: Basin scale estimates of evapotranspiration using GRACE and other observations. Geophys. Res. Lett., 31, L20504, https://doi.org/10.1029/2004GL020873.

Rui, H., and H. Beaudoing, 2020: README Document for NASA GLDAS Version 2 Data Products. NASA, 22 pp., https:// hydro1.gesdisc.eosdis.nasa.gov/data/GLDAS/README_ GLDAS2.pdf.

Save, H., S. Bettadpur, and B. D. Tapley, 2016: High resolution CSR GRACE RL05 mascons. J. Geophys. Res. Solid Earth, 121, 7547-7569, https://doi.org/10.1002/2016JB013007.

Schär, C., D. Lüthi, U. Beyerle, and E. Heise, 1999: The soilprecipitation feedback: A process study with a regional climate model. J. Climate, 12, 722-741, https://doi.org/10.1175/ 1520-0442(1999)012<0722:TSPFAP>2.0.CO;2.

Seneviratne, S. I., T. Corti, E. L. Davin, M. Hirschi, E. B. Jaeger, I. Lehner, B. Orlowsky, and A. J. Teuling, 2010: Investigating soil moisture-climate interactions in a changing climate: A review. Earth-Sci. Rev., 99, 125-161, https://doi.org/10.1016/ j.earscirev.2010.02.004.

Swenson, S., and D. M. Lawrence, 2014: Assessing a dry surface layer-based soil resistance parameterization for the Community Land Model using GRACE and FLUXNET-MTE data. J. Geophys. Res. Atmos., 119, 10 229-10312, https://doi.org/ 10.1002/2014JD022314.

_ J. Wahr, and P. C. D. Milly, 2003: Estimated accuracies of regional water storage variations inferred from the Gravity Recovery and Climate Experiment (GRACE). Water Resour. Res., 39, 1223, https://doi.org/10.1029/2002WR001808.
— P. J. F. Yeh, J. Wahr, and J. Famiglietti, 2006: A comparison of terrestrial water storage variations from GRACE with in situ measurements from Illinois. Geophys. Res. Lett., 33, L16401, https://doi.org/10.1029/2006GL026962.

Syed, T. H., J. S. Famiglietti, M. Rodell, J. Chen, and C. R. Wilson, 2008: Analysis of terrestrial water storage changes from GRACE and GLDAS. Water Resour. Res., 44, W02433, https://doi.org/10.1029/2006WR005779.

Tapley, B. D., S. Bettadpur, M. Watkins, and C. Reigber, 2004: The Gravity Recovery and Climate Experiment: Mission overview and early results. Geophys. Res. Lett., 31, L09607, https:// doi.org/10.1029/2004GL019920.

Taylor, C. M., R. A. de Jeu, F. Guichard, P. P. Harris, and W. A. Dorigo, 2012: Afternoon rain more likely over drier soils. Nature, 489, 423-426, https://doi.org/10.1038/nature11377.

Watkins, M. M., D. N. Wiese, D.-N. Yuan, C. Boening, and F. W. Landerer, 2015: Improved methods for observing Earth's time variable mass distribution with GRACE using spherical cap mascons. J. Geophys. Res. Solid Earth, 120, 2648-2671, https:// doi.org/10.1002/2014JB011547.

Wei, J., R. E. Dickinson, and H. Chen, 2008: A negative soil moistureprecipitation relationship and its causes. J. Hydrometeor., 9, 13641376, https://doi.org/10.1175/2008JHM955.1.

Wey, H.-W., M.-H. Lo, S.-Y. Lee, J.-Y. Yu, and H.-H. Hsu, 2015: Potential impacts of wintertime soil moisture anomalies from agricultural irrigation at low latitudes on regional and global climates. Geophys. Res. Lett., 42, 8605-8614, https://doi.org/ 10.1002/2015GL065883.

Wiese, D. N., D.-N. Yuan, C. Boening, F. W. Landerer, M. M. Watkins, 2015: JPL GRACE Mascon Ocean, Ice, and Hydrology Equivalent Water Height JPL RL05M.1. Ver. 1. PO.DAAC, accessed 19 June 2015, https://doi.org/10.5067/ TEMSC-OCL05.

— , F. W. Landerer, and M. M. Watkins, 2016: Quantifying and reducing leakage errors in the JPL RL05M GRACE mascon solution. Water Resour. Res., 52, 7490-7502, https://doi.org/ 10.1002/2016WR019344.

- D.-N. Yuan, C. Boening, F. W. Landerer, M. M. Watkins, 2018: JPL GRACE Mascon Ocean, Ice, and Hydrology Equivalent Water Height Release 06 Coastal Resolution Improvement (CRI) Filtered Version 1.0. PO.DAAC, accessed 1 July 2019, https://doi.org/10.5067/TEMSC-3MJC6.

Yin, J., J. D. Albertson, J. R. Rigby, and A. Porporato, 2015: Land and atmospheric controls on initiation and intensity of moist convection: CAPE dynamics and LCL crossings. Water Resour. Res., 51, 8476-8493, https://doi.org/10.1002/ 2015WR017286.

Zhao, M., H. Zhang, and I. Dharssi, 2019: On the soil moisture memory and influence on coupled seasonal forecasts over Australia. Climate Dyn., 52, 7085-7109, https://doi.org/ 10.1007/s00382-018-4566-8. 